\title{
EDUCAÇÃO E DEVER DE MEMÓRIA: AS POSSIBILIDADES DE EMANCIPAÇÃO NA SOCIEDADE DE MERCAD0 ${ }^{1}$
}

\author{
Pedro Savi Neto (PUC-RS)*
}

\section{RESUMO}

0 presente artigo, fundamentado em uma pesquisa teórica, tem como objetivo analisar algumas consequências do direcionamento cada vez mais explícito e intenso da educação para o atendimento de interesses econômicos, a partir do ferramental teórico da Teoria Crítica da Sociedade, em especial do Novo Imperativo Categórico de Theodor W. Adorno. Partindo desse relacionamento cada vez mais íntimo, pretende-se pensar as possibilidades de emancipação do sujeito pela educação no interior de um mundo administrado por interesses econômicos. Em contraposição a isso, será tensionada a tarefa fundamental da educação com o dever de memória, tal qual tematizado por Reyes Mate.

Palavras-chave: Emancipação. Dever de memória. Theodor W. Adorno.

\section{ABSTRACT}

\section{EDUCATION AND DUTY OF MEMORY: THE POSSIBILITIES OF EMANCIPATION IN THE MARKET SOCIETY}

This article, based on a theoretical research, aims to analyze some consequences of the increasingly explicit and intense direction of education for the attendance of economic interests, based on the theoretical tool of the Critical Theory of Society, especially the New Categorical Imperative by Theodor W. Adorno. Starting from this increasingly intimate relationship, we intend to think about the possibilities of emancipation of the subject by education within a world managed by economic interests. In contrast, the fundamental task of education with the duty of memory, as thematized by Reyes Mate, will be stressed.

Keywords: Emancipation. Duty of memory. Theodor W. Adorno.

1 O presente trabalho foi realizado com apoio da Coordenação de Aperfeiçoamento de Pessoal Nível Superior (CAPES) - Código de Financiamento 001.

* Doutor em Educação pela Pontifícia Universidade Católica do Rio Grande do Sul (PUC-RS). Professor Colaborador do Programa de Pós-Graduação em Educação da Pontifícia Universidade Católica do Rio Grande do Sul (PUC-RS). Bolsista PNPD/Capes. E-mail: pedro.savi@pucrs.br 


\section{RESUMEN}

\section{EDUCACIÓN Y DEBER DE MEMORIA: LAS POSIBILIDADES DE EMANCIPACIÓN EN LA SOCIEDAD DE MERCADO}

El presente artículo, fundamentado en una investigación teórica, tiene como objetivo analizar algunas consecuencias del direccionamiento cada vez más explícito e intenso de la educación para la atención de intereses económicos, a partir del instrumento teórico de la Teoría Crítica de la Sociedad, en especial del Nuevo Imperativo Categórico de Theodor W. Adorno. A partir de esa relación cada vez más íntima, se pretende pensar las posibilidades de emancipación del sujeto por la educación en el interior de un mundo administrado por intereses económicos. En contraposición a ello, se tensará la tarea fundamental de la educación con el deber de memoria, tal cual tematizado por Reyes Mate.

Palabras clave: Emancipación. Deber de memoria. Theodor W. Adorno.

\section{Apresentação: Theodor W. Adorno e a Teoria Crítica da Sociedade ${ }^{2}$}

0 presente artigo tem como objetivo analisar algumas consequências do direcionamento cada vez mais explícito e intenso da educação para o atendimento de interesses econômicos, a partir do ferramental teórico da Teoria Crítica da Sociedade, em especial do Novo Imperativo Categórico (NIC) de Theodor W. Adorno. Partindo desse relacionamento cada vez mais íntimo, pretende-se pensar as possibilidades de emancipação do sujeito pela educação no interior de um mundo administrado por interesses econômicos. Em contraposição a isso, será tensionada a tarefa fundamental da educação com o dever de memória, tal qual tematizado por Reyes Mate.

Theodor W. Adorno (11/09/1903 06/08/1969), filósofo alemão de origem judaica, foi um dos principais integrantes da primeira geração da chamada Escola de Frankfurt, grupo de pensadores marxistas não ortodoxos que se reuniu da década de $1920 \mathrm{em}$ torno de um objetivo em comum: promover uma crítica abrangente da sociedade na qual viviam. No momento da formação do grupo,

2 Este artigo é parte modificada da tese de doutoramento do autor (SAVI NETO, 2017). o objeto da reflexão crítica foi a Europa, especialmente a Alemanha do período anterior à Segunda Guerra Mundial; depois, em um exílio forçado, as análises, especialmente de Adorno e Horkheimer, tiveram como principal referência a sociedade americana. Contudo, e nessa medida justifica-se a pertinência das referidas análises para servirem de base à presente reflexão, os estudos realizados se aplicam perfeitamente à sociedade contemporânea, marcada pelo capitalismo tardio, ${ }^{3}$ na qual os interesses de mercado vêm avançando por cada vez mais por instâncias de interesse público.

Para além de propriamente uma Escola (de Frankfurt), é possível identificar a chamada Teoria Crítica da Sociedade como forma de expressão filosófica caracterizada por pesquisas e intervenções teóricas sobre questões filosóficas, sociológicas, econômicas, sociais, culturais, estéticas e sua relação com o capitalismo (WIGGERSHAUS, 2002). Eles entendiam que,

3 Adorno denomina o período posterior à Segunda Guerra Mundial com a expressão capitalismo tardio no lugar de "sociedade industrial" por entender que aquele termo abarca melhor a noção de "[...] forma social que [...] se caracteriza pela conversão progressiva de ciência e tecnologia em forças produtivas" (MAAR, 1995, p. 19). Período marcado pela crescente burocratização e administração de todas as esferas da vida pela lógica do capital. Adorno prossegue na crítica de Marx ao capitalismo, contudo com abordagem própria e distinta, com ênfase ao caráter fetichista da mercadoria que passa a contaminar todas as relações sociais na sociedade, inclusive as relações educacionais. 
diante da sociedade burguesa que começava a mostrar com maior clareza seu caráter injusto na Alemanha da década de 1920, a crítica não se tratava de mera opção teórica, mas de um caminho inevitavelmente necessário. Essa crítica filosófica à chamada Teoria Tradicional estava radicalmente comprometida a pensar a injustiça social e as suas causas. De acordo com Souza (1996, p. 34, grifo do autor):

\begin{abstract}
[...] cada um a seu modo, cada pensador deixa transparecer o que constitui a medula e o foco gerador de sua particular discursividade, o que dá sentido aos seus esforços discursivos, sua básica motivação. Trata-se de uma inquietação ética radical, tão profunda quanto descontente com as reais condições do universo que a sensibilidade particular deste grupo de filósofos conseguia captar.
\end{abstract}

A referida sensibilidade particular do grupo pode ser entendida, em parte, porque os pensadores da chamada primeira geração eram judeus; o que significa dizer que, por maior reconhecimento intelectual e entrada na burguesia que pudessem eventualmente obter, permaneceram sempre não-assimilados à sociedade alemã. Para eles, a marginalidade não era um conceito, mas uma condição de vida a partir da qual estruturaram as suas obras, conforme esclarece Wiggershaus (2002, p. 37):

A sua maneira, os judeus deviam ter também, não menos que os proletários, um sentimento aguçado de alienação e de inautenticidade da vida na sociedade burguesa capitalista. Mesmo que os judeus fossem em grande parte privilegiados em relação aos proletários, nem por isso até os judeus privilegiados escapavam ao seu judaísmo. Os trabalhadores privilegiados, em contrapartida, deixavam de ser trabalhadores, quando muito na segunda geração. Mas era mais difícil, para eles, atingir a condição de privilegiados. A experiência da tenacidade da alienação social que tinham os judeus criava uma certa semelhança com a experiência da tenacidade da alienação social, regra geral para os trabalhadores. Isso não implicava obrigatoriamente uma atitude de solidariedade em meio aos trabalhadores. Mas conduzia, em todo caso, frequentemente, a uma crítica radical da socie- dade, que correspondia aos interesses objetivos dos trabalhadores.

Contudo, o referido grupo de pensadores soube transcender a sua condição pessoal de marginalidade na análise da opressão e da dominação exercida no âmbito da sociedade burguesa sobre outros grupos igualmente vulneráveis e sobre as possibilidades de emancipação desses grupos em uma sociedade dominada por interesses econômicos. Tal como esclareceu Max Horkheimer (1980), no artigo Teoria Tradicional e Teoria Crítica, de 1937, a Teoria Crítica da Sociedade está fundamentada em dois princípios básicos da teoria social: "o comportamento crítico e a orientação para a emancipação" (GOMES, 2015, p. 145). Jorge Coelho Soares, no prefácio à edição brasileira da obra A Escola de Frankfurt: história, desenvolvimento teórico, significação política (SOARES, 2002 apud WIGGERSHAUS, 2002, p. 11), chama atenção para as preocupações centrais desse grupo de pensadores frankfurtianos.

Produziram, assim, um conjunto de reflexões, objetivado em inúmeros livros e artigos, que tentou dar conta, de forma tensional, dos grandes dilemas de nossa vida no momento histórico de radicalidade de uma modernidade que se apresenta como a Esfinge de nosso tempo. E entre os dois polos - o de emancipação e o de exploração - que essa modernidade nos colocou como seu principal enigma, a Escola sempre optou por apostar na ênfase da contradição e na negatividade, como exercício cotidiano de lucidez.

A percepção da injustiça a partir da visão do marginal e a necessidade de dar vazão a isso filosoficamente fez com que os pensadores frankfurtianos se obrigassem a mudar, inclusive, a forma de expressão filosófica, argumentando criticamente contra as filosofias de caráter idealista que estavam na base da constituição da sociedade burguesa. Não faria sentido uma crítica que pretendesse romper com a lógica vigente na sociedade burguesa, mas que se valesse das mesmas ferramentas que serviram de base para a construção e fundamentação da sociedade objeto da crítica 
(BUCK-MORSS, 1981, p. 130). Assim, sob a influência da dialética de Hegel, construíram uma filosofia que se propunha a explorar as contradições da realidade; contudo, diferentemente da dialética hegeliana, tratava-se de uma dialética negativa, que não se resolvia em sínteses:

Como en Hegel, la contradicción, con la negación como su principio lógico, dotó a su pensamiento de estructura dinámica y proporcionó la fuerza motora para la reflexión crítica. Pero mientras Hegel veía en la negatividad el movimiento del concepto hacia su 'otro', sólo un momento dentro de un proceso mayor hacia la consumación sistemática, Adorno no veía posibilidad alguna de que una argumentación se detuviera en la síntesis inequívoca. Hizo de la negatividad el signo distintivo de su pensamiento precisamente porque creía que Hegel se había equivocado: razón y realidad no coincidían. (BUCK-MORSS, 1981, p. 139).

Merece registro que, embora o pensamento crítico caracterize a forma de expressão geral dos autores da Teoria Crítica, Adorno foi aquele que levou mais longe o desdobramento do conceito de dialética negativa como ferramenta filosófica de crítica para pensar a possibilidade de emancipação.

Além dos elementos já referidos, a urgência e a atualidade do tema são fundamentadas pela continuidade das pesquisas em Teoria Crítica na Universidade de Frankfurt, especialmente pela chamada Teoria Crítica da Educação, com protagonismo de Andreas Gruschka, com ênfase na chamada frieza burguesa (conceito utilizado por Adorno e desenvolvido por Gruschka) decorrente do manifesto e atual avanço dos interesses econômicos sobre a educação na Alemanha:

Trata-se, conforme a análise de Gruschka (2014 e 2008), de uma espécie de 'imperativo econômico', com sofisticados mecanismos de integração social, que se apropria da escola e induz a mediação estratégica de uma lógica própria e sistêmica. Nessa lógica funcional e calculista, conforme a dinâmica e as exigências do mercado, o conteúdo da formação e da ciência deslocase sob a regência dos imperativos de consumo, isso exige a renúncia do conteúdo da formação cuja mediação pode ser observada inclusive na escola, por intermédio de sofisticados mecanismos de integração social, como a aula. (GOMES, 2015, p. 152-153, grifo do autor).

O progressivo avanço dos interesses econômicos sobre a educação é uma questão grave e de interesse mundial. Sob o falacioso argumento da erradicação da pobreza, os organismos financeiros internacionais abrem as portas dos sistemas educacionais nacionais para o capital especulativo internacional, retirando a educação do âmbito dos direitos públicos fundamentais e de responsabilidade do Estado (enquanto interesse de todos) e a transformando em um serviço. ${ }^{4}$ Tudo isso pressupõe uma série de orientações exclusivamente econômicas que se distanciam, especialmente, da concepção histórica humanista da educação como um direito ou bem público, comprometida com a emancipação do sujeito, submetendo-a de forma absoluta à lógica de mercado e à necessidade de lucro.

\section{Educação e mercado}

O tema da emancipação é recorrente na obra de Adorno, tratado de forma articulada com a educação: “[...] a ideia da emancipação [...] precisa ser inserida no pensamento e também na prática educacional" (ADORNO, 1995, p. 143). Adorno aborda os temas da formação, da educação e da emancipação em diversas passagens e em alguns textos específicos da sua obra, evidenciando: a) a centralidade de tal preocupação para ele; e b) o seu protagonismo dentre os demais representantes da Teoria Crítica da Sociedade no desenvolvimento de uma teoria crítica da educação (GOMES, 2015, p. 146).

Para a compreensão adequada da questão proposta pelo presente texto em sua relação com a obra adorniana, faz-se necessário referir

4 Em 1995, a OMC incluiu na definição de serviço, constante do chamado Acordo Geral sobre Comércio de Serviços, a cultura, a saúde e a educação. 
a existência de um forte entrelaçamento dos conceitos de educação (Erziehung), emancipação (Mündigkeit) e formação (Bildung - que pode ser entendida como formação cultural), a ponto de Zuin, Pucci e Ramos-de-Oliveira (2000, p. 117) afirmar que "[...] para o frankfurtiano, educação é o mesmo que emancipação. 0 [...] que os gregos chamaram de paidéia; os alemães denominaram Bildung e nós designamos formação" (GOERGEN, 2009, p. 26). Com relação à escolha da palavra emancipação, Vilela (2007, p. 235-236) esclarece que:

Para entender o Theodor Adorno desse conjunto de textos [referindo-se à obra Educação e emancipação], parece-nos fundamental esclarecer o termo alemão, utilizado por ele, para indicar seu pensamento sobre a escola e a Educação, pois o vocábulo português "emancipação" não revela o sentido pleno tomado pelo teórico. Ao escolher a palavra, Adorno procurou, com ela, revelar a essência do seu pensamento: a educação e o processo social de dominação apresentam uma mesma raiz. Mund significa 'boca'. Mündigkeit significa a capacidade de falar pela própria boca, falar por si mesmo; mas, para essa condição, o sujeito precisa ser capaz de pensar por si mesmo. Entretanto, o processo social de dominação retirou do homem a capacidade de pensar por conta própria, retirou dele a capacidade de autonomia das suas ações, de falar e de agir por si mesmo.

Em Adorno, a formação é a relação dialética que se estabelece entre sujeito e sociedade e, sendo a educação formal determinada pelas normas da sociedade, mesmo que distintas em essência, educação, educação formal e formação estão sujeitas ao mesmo campo de forças. Pode-se entender a educação formal como parte do processo de educação que, por sua vez, é parte do processo de formação; e todos esses processos tensionam a relação entre sujeito e sociedade. Para Maar (1995, p. 14-15):

A íntima vinculação entre a questão educacional e formativa e a reflexão teórica social, política e filosófica constitui a manifestação mais direta do núcleo temático essencial ao conjunto da chamada Escola de Frankfurt: a relação entre teoria e prática. Em Adorno, a teoria social é na realidade uma abordagem formativa, e a reflexão educacional constitui uma focalização políticosocial. Uma educação política.

Tanto é verdade que Educação e emancipação foi o nome atribuído por Gerd Kadelbach a uma série de conversas havidas entre Adorno e Helmut Becker5 e transmitidas pela rádio Hessen entre 1960 e 1969 (CUNHA, 2007, p. 95). 0 núcleo desse compilado de textos pode ser resumido, de acordo com o prefácio à edição brasileira de Maar (1995, p. 11), da seguinte maneira: "Após Auschwitz, é preciso elaborar o passado e criticar o presente prejudicado, evitando que este se perdure e, assim, que aquele se repita". Os textos cronologicamente estruturados (títulos dos capítulos), mas sem uma organização linear, serviram de base para a construção da frase retrocitada de Maar: $O$ que significa elaborar o passado ("Após Auschwitz, é preciso elaborar o passado [...]"); A filosofia e os professores, Televisão e formação e Tabus acerca do magistério ("[...] e criticar o presente prejudicado [...]"); Educação após Auschwitz e Educação - para quê? ("[...] evitando que este se perdure [...]"); Educação contra a barbárie e Educação e Emancipação (“[...] e, assim, que aquele se repita.") (MAAR, 1995).

Mesmo sem ter a pretensão de esboçar um projeto educacional, Adorno realizou as suas análises vinculando a educação emancipatória com a desbarbarização da humanidade. Educar quer dizer, para Adorno, resistir à barbárie, preocupação central presente em toda a sua filosofia moral e elevada à condição de novo imperativo categórico (NIC) formulado após a Segunda Guerra Mundial: "[...] instaurai o vosso pensamento e a vossa ação de tal modo que Auschwitz não se repita, de tal modo que nada desse gênero aconteça" (ADORNO, 2009, p. 303). ${ }^{6}$ A construção kantiana original é "age

5 Diretor do Instituto de Pesquisas Educacionais da Sociedade Max Planck em Berlim.

6 "O nome Auschwitz, utilizado como sinédoque para referirse ao genocídio judeu, é preferível a outros termos como Holocausto (carregado de significação teológica), Shoah (caracterização como catástrofe incomparável dentro da história do povo judeu) ou Jurban (continuidade do genocídio com outras catástrofes de tal história)" (YOUNG, 1997 apud ZAMORA, 2008, p. 26). 
só segundo máxima tal que possas ao mesmo tempo querer que ela se torne lei universal" (KANT, 2004, p. 51).

O imperativo categórico é uma construção kantiana da qual Adorno se apropria mudando o conteúdo. Em Kant esse conceito é um momento da razão prática, quer dizer, da ética. Em Adorno, no entanto, faz parte da metafísica na secção que traz como título Metafísica depois de Auschwitz. 0 mal no mundo não convoca apenas o indivíduo, mas a metafísica, porque o que está em jogo não é só o ser bom, mas o ser homem. (MATE, 2005, p. 125).

A possibilidade de aplicação de um imperativo categórico passa por duas dimensões fundamentais e interdependentes: indivíduo e sociedade. ${ }^{7}$ A compreensão das possibilidades de construção de uma educação comprometida com o dever de memória depende da compreensão anterior da caracterização adorniana da sociedade moderna, pois “[...] não há emancipação possível sem a emancipação da sociedade." (ADORNO, 1993, p. 164).

Adorno concorda com Kant no sentido de que a emancipação é o objetivo da educação; eles, contudo, divergem sobre a sociedade burguesa ser ou não uma organização social favorável à emancipação. Para Kant, a sociedade iluminista nascente, ou do esclarecimento, ${ }^{8}$

7 "A psicologia social indica a relação entre o indivíduo e a sociedade; deve ter a sua especificidade que não coincida nem com a psicologia, nem com a sociologia. Adorno entende essa relação de maneira a não restringir esse objeto a uma mera 'interação simétrica' entre dois fenômenos. Primeiro, porque critica a sociologia pensada sem indivíduos e a psicologia voltada unicamente ao seu objeto, por desconhecer que esse se desenvolve socialmente e que é a sociedade e a cultura que lhe permitem se constituir como indivíduo; segundo, porque essa relação é histórica e, assim, a possibilidade do indivíduo ser mais ou menos diferenciado depende da configuração social e de sua necessidade de reprodução (não é casual que o autor enfatize que a sociedade produz os homens que necessita para se manter tal como é); terceiro, porque a sociedade não determina externamente a formação do indivíduo, mas de forma imanente; e por fim, porque na atualidade a sociedade tem primazia acerca da determinação do comportamento individual." (CROCHÍK, 2008, p. 297-298).

8 Guido A. de Almeida, tradutor da Dialética do esclarecimento, faz as seguintes observações sobre o termo esclarecimento: "A tradução de Aufklärung por esclarecimento requer uma explicação: por que não recorremos ao termo iluminismo, ou ilustração, que são expressões mais usuais entre nós oferecia as condições necessárias para a saída do sujeito de sua menoridade; para Adorno, entretanto, além de não oferecer as condições necessárias, ela foi (como continua sendo) uma das principais responsáveis pela manutenção do estado de menoridade do sujeito. Suas divergências nascem, especialmente (mas não somente), do local e do tempo de fala de cada um: enquanto Kant viveu o nascimento do esclarecimento e compartilhou do otimismo da razão que se acreditava libertadora, ${ }^{9}$ Adorno sofreu na carne a potencialização da barbárie viabilizada por essa mesma razão.

No ensaio que citei no início, referente à pergunta 'vivemos atualmente em uma época esclarecida'. Kant respondeu: 'Não, mas certamente em uma época de esclarecimento'. Nestes termos ele determinou a emancipação de um modo inteiramente consequente, não como uma categoria estática, mas como uma categoria dinâmica, como um vir a ser e não um ser. Se atualmente ainda podemos afirmar que vivemos numa

para designar aquilo que também conhecemos como a Época ou a Filosofia das Luzes? Em primeiro lugar, como não poderia deixar de ser, por uma questão de maior fidelidade: a expressão esclarecimento traduz com perfeição não apenas o significado histórico-filosófico, mas também o sentido mais amplo que o termo encontra em Adorno e Horkheimer, bem como o significado corrente de Aufklärung na linguagem ordinária. É bom que se note, antes de mais nada, que Aufklärung não é apenas um conceito histórico-filosófico, mas uma expressão familiar da língua alemã, que encontra um correspondente exato na palavra portuguesa esclarecimento, por exemplo em contextos como: sexuelle Aufklärung (esclarecimento sexual) ou politische Aufklärung (esclarecimento político). Neste sentido, as duas palavras designam, em alemão e em português, o processo pelo qual uma pessoa vence as trevas da ignorância e do preconceito em questões de ordem prática (religiosas, políticas, sexuais, etc.)" (ADORNO; HORKHEIMER, 1985. p. 7).

9 "Se for feita então a pergunta: 'vivemos agora em uma época esclarecida [aufgeklärten]?', a resposta será: 'não, vivemos em uma época de esclarecimento [aufklärung]'. Falta ainda muito para que os homens, nas condições atuais, tomados em conjunto, estejam já numa situação, ou possam ser colocados nela, na qual em matéria religiosa sejam capazes de fazer uso seguro e bom de seu próprio entendimento sem serem dirigidos por outrem. Somente temos claros indícios de que agora lhes foi aberto o campo no qual podem lançar-se livremente a trabalhar e tornarem progressivamente menores os obstáculos ao esclarecimento [aufklärung] geral ou à saída deles, homens, de sua menoridade, da qual são culpados. Considerada sob este aspecto, esta época é a época do esclarecimento [aufklärung] ou o século de Frederico." (KANT, 2005, p. 69-70). 
época de esclarecimento, isto tornou-se muito questionável em face da pressão inimaginável exercida sobre as pessoas, seja pela própria organização do mundo, seja num sentido mais amplo, pelo controle planificado até mesmo de toda realidade interior pela indústria cultural. Se não quisermos aplicar a palavra 'emancipação' num sentido meramente retórico, ele próprio tão vazio como o discurso dos compromissos que as outras senhorias empunham em frente à emancipação, então por certo é preciso começar a ver efetivamente as enormes dificuldades que se opõem à emancipação nesta organização de mundo. (ADORNO, 1995, p. 181).

Na citação, percebe-se que Adorno aponta duas formas de dominação do sujeito que obliteram a sua emancipação e mantêm a barbárie: a própria forma de organização do mundo e o controle planificado exercido pela indústria cultural, que impede a formação cultural. A primeira das formas de dominação nasce com a razão e se estabelece na relação entre natureza e cultura; a segunda nasce com o estado burguês e reside na administração do mundo pelos interesses de mercado. ${ }^{10}$ Ambas afetam diretamente o processo de formação humana e prejudicam a emancipação do sujeito, no contexto de não-liberdade da sociedade administrada pelos interesses burgueses:

[...] é que a organização social em que vivemos continua sendo heterônoma, isto é, nenhuma pessoa pode existir na sociedade atual realmente conforme suas próprias determinações; enquanto isto ocorre, a sociedade forma as pessoas mediante inúmeros canais e instâncias mediadoras, de um modo tal que tudo absorvem e aceitam nos termos desta configuração heterônoma que se desviou de si mesma em sua consciência. É claro que isto chega até as instituições, até a discussão acerca da educação política e outras questões semelhantes. 0

10 Segundo Crochík (2008, p. 300-301): “Os objetos principais dos estudos contidos nessa obra [referindo-se à $\mathrm{DE}]$ não são somente o fascismo e o antissemitismo, mas o que os gera: a transformação da sociedade liberal para a administrada, isto é, um sistema político fascista como consequência inevitável do capitalismo de monopólios, o que não os impediu de fazer uma teoria da dominação baseada na relação natureza-cultura, isto é, entender a dominação como algo transcendente à própria economia, ainda que, como salientado antes, se expresse também por ela." problema propriamente dito da emancipação hoje é se e como a gente - e quem é a 'gente', eis uma grande questão a mais - pode enfrentá-lo. (ADORNO, 1995, p. 181-182).

Tal forma de tratamento do tema demonstra a convicção de Adorno de que moralidade e educabilidade são duas dimensões humanas indissociavelmente vinculadas. Adorno teve o cuidado de relacionar seu NIC com a sua preocupação com a educação: “A exigência que Auschwitz não se repita é a primeira de todas para a educação" (ADORNO, 1995, p. 119). Portanto, é fundamental refletir sobre qual tipo de contexto social, qual tipo de educação, participa (por ação e omissão) da formação de sujeitos moralmente fracos a ponto de dissolverem-se no coletivo e serem capazes de participação em um projeto de aniquilação de outros seres humanos. 0 referido enfraquecimento do sujeito, especialmente da sua moralidade, deve ser compreendido a partir de uma racionalidade de dominação social engajada em tornar invisível a injustiça, o sofrimento e as próprias vítimas. Nesse ponto reside a importância fundamental do NIC em sua relação com a educação: além de inserir o sujeito no fluxo histórico, deve, também e fundamentalmente, revelar sobre quais processos de esquecimento a sociedade está construída e as consequências disso para o presente.

\section{Dever de memória}

Para que a concepção de emancipação na filosofia de Adorno adquira a materialidade pretendida por ele como resposta às filosofias idealistas, não se pode mirar Auschwitz isoladamente, como um acontecimento pontual, regional e temporalmente inserido em um contexto único na história, mas deve compreender-se a sua relação com a racionalidade que prometeu promover a civilização, mas promoveu barbárie. De todas as representações possíveis e terríveis de Auschwitz, o caráter exemplar que Adorno confere ao referido evento guarda relação com o fato de que se tratou 
de um projeto de esquecimento como nenhum outro: "Deve-se levar em consideração, com efeito, que Auschwitz não foi apenas uma gigantesca fábrica de morte, mas também um projeto de esquecimento." (MATE, 2005, p. 7). Auschwitz representou a assunção explícita do caráter de exclusão (eliminação) da diferença; do extermínio daqueles que não interessa(va) $\mathrm{m}$ à sociedade regida pelo capitalismo tardio.

Nesse aspecto, o holocausto somente se diferenciou da lógica da sociedade regida pelos interesses burgueses no tocante à intensidade da exclusão (eliminação); contudo, em essência, somente repetiu a lógica da sociedade cada vez mais contaminada pelos interesses de mercado, na qual tudo aquilo que não pode ser capturado pela racionalidade esclarecida é excluído e relegado ao esquecimento: “[...] a memória, o tempo e a lembrança são liquidados pela própria sociedade burguesa em seu desenvolvimento, como se fossem uma espécie de resto irracional." (ADORNO, 1995, p. 33).

Adorno elabora seu NIC fundado no dever de memória como forma de não repetir a barbárie, ou seja, na responsabilidade ética do sujeito para com as gerações anteriores que sofreram e que perderam a vida em nome do presente. O NIC tem como objetivo interromper a constante "incursión de la humanidad en inhumanidad" (TIEDEMANN, 2007, p. 16), contrapondo a onda de violência que acompanha o ser humano ao longo de toda sua história. ${ }^{11}$ Na missão de evitar a repetição da barbárie, a educação adquire protagonismo, pois se trata da dimensão fundamental para colocar em relação o conteúdo do passado (no pensamento de Adorno, especialmente a barbárie passada) como aprendizado para o presente, visando a evitar que no futuro se repita. Essa ligação das gerações humanas ao longo do fluxo histórico é fundamental à educação: fazer conversar passado, presente e futuro. Tal questão é exemplarmente resgatada por Hannah Arendt (2007, p. 247):

11 A presença da violência ao longo de toda a história da humanidade é demonstrada na obra Violência na História, de Regina Bustamante Moura (2009).
O que nos diz respeito a todos e, consequentemente, não pode ser confiado à pedagogia enquanto ciência especializada, é a relação entre adultos e crianças em geral ou, em termos ainda mais gerais e exatos, a nossa relação com o facto da natalidade: o facto de que todos chegamos ao mundo pelo nascimento e que é pelo nascimento que este mundo constantemente se renova. A educação é assim o ponto em que se decide se se ama suficientemente o mundo para assumir responsabilidade por ele e, mais ainda, para o salvar da ruína que seria inevitável sem a renovação, sem a chegada dos novos e dos jovens. A educação é também o lugar em que se decide se se amam suficientemente as nossas crianças para não as expulsar do nosso mundo deixando-as entregues a si próprias, para não lhes retirar a possibilidade de realizar qualquer coisa de novo, qualquer coisa que não tínhamos previsto, para, ao invés, antecipadamente as preparar para a tarefa de renovação de um mundo comum.

A relação entre as gerações no pensamento de Arendt pressupõe uma questão moral: a assunção da responsabilidade pelo mundo e pelas gerações futuras. Essa ligação entre as gerações engendra o fundamento central da questão política enquanto aquilo que diz respeito a todos (inclusive com relação aos mortos e aos que ainda não nasceram). A partir disso, a educação não pode ser despida de um caráter político moralmente determinado (essa ligação é fundamental para Adorno). Esse "não pode" tem viés duplo: "não pode" como "não deve" e "não pode" na medida em que a educação é indissociável de seu caráter político (a desvinculação de educação e política é, por si, uma medida de cunho político ${ }^{12}$ - das mais perigosas).

12 No Brasil, tem gerado bastante polêmica o chamado Projeto Escola Sem Partido, composto das propostas de Lei no 193/2016, 1.411/2015 e 867/2015: “A ideia central do projeto é de que seria possível e desejável uma desvinculação entre os conhecimentos científicos e os posicionamentos ideológicos, políticos e culturais. 0 que faz, porém, é delimitar, a partir de um único ponto de vista, o que é considerado ideológico e o que é válido como conhecimento científico, ignorando que todo conhecimento é fruto de uma elaboração que atende às perspectivas sóciohistórico-político-culturais. Todo conhecimento, portanto, é ideológico!" (DUTRA; MORENO, 2016). Na linha do que afirma Foucault (1996, p. 44): "Todo sistema de educação é uma maneira política de manter ou de modificar a apropriação dos discursos, com os saberes e os poderes que eles trazem consigo." 
As ciências da educação, no entanto, não podem se restringir a uma visão técnica, pois a educação tem um papel político que transcende seus objetivos estritamente científico-pedagógicos. Toda educação escolar é projeto político. Além disso, seria total ingenuidade imaginar que os conhecimentos científicos estejam livres dos condicionamentos éticos e ideológicos. Se as categorias do ser e do dever ser são dimensões fundamentais do ato educativo, as funções da educação escolar adquirem um caráter mais político do que científico. (PAVIANI, 1983, p. 34).

A crise que atinge a educação, especialmente a educação formal, está diretamente relacionada com a destruição de seu caráter político -público (GOERGEN, 2005). A educação é cada vez menos identificada como uma instância de resguardo de questões fundamentais ao ser humano e à vida do planeta e cada vez mais contaminada pela lógica do capitalismo tardio, que reduz a sua tarefa à mera preparação para o mercado de trabalho:

[...] desde o Iluminismo a educação escolar é considerada a instância primeira para praticar-se o moralmente desejável, para auxiliar a emancipação do indivíduo; porém, as promessas e as metas do Iluminismo demandam algo impossível à/na escola da sociedade burguesa, fundamentada no princípio da troca. 0 processo educacional aspira ao desenvolvimento da solidariedade, da justiça social nos estudantes; porém, as normatizações que presidem o desenrolar do ambiente formativo no interior da escola se deixam guiar pelos princípios da sociedade burguesa, em que os interesses individuais prevalecem sobre os interesses coletivos. Essa é a razão por que a educação, mais que qualquer outro campo comprometido com o esclarecimento, não consegue através dos tempos desenvolver seu potencial libertador e formativo. [...] a moral da pedagogia está atrelada totalmente à imoralidade vigente nas estruturas da sociedade. (PUCCI, 2014, p. XIX).

0 contato desde muito cedo por parte das novas gerações com o individualismo, com a competição e com outras estruturas inerentes ao mercado, por um lado, e a falta de oportunidade para exercitar o espírito coletivo, a gratuidade das ações, dentre outras características fundamentais para a emancipação do sujeito para além do mercado de trabalho, por outro, determinam que o sujeito não encontra oportunidade de desenvolver um comportamento ético. A escola, ao invés de afirmar-se como um espaço de constituição de um sujeito ético (comprometido com os outros, com a história e com a natureza), funciona simplesmente como uma fábrica de trabalhadores para o mercado de trabalho. Nesse sentido, é fundamental que seja exercida a crítica devidamente fundamentada na identificação das artimanhas da racionalidade de mercado, pois ainda mais grave do que a transformação da educação em mera preparação para o mercado de trabalho é a aura de moralidade que a torna ideologicamente mais perigosa.

No caso da escola, por exemplo, certamente não há diretor, nem orientador ou professor que não se digam comprometidos com a relevância da ética para o agir educativo. Mesmo assim, ao primeiro olhar sobre a estrutura curricular e o quotidiano escolar, constatamos que a ética ocupa um lugar bastante singelo, muitas vezes restrito a um recorte disciplinar ou, quando muito, a uma atividade transversal. (GOERGEN, 2005, p. 984-985).

Diante desse quadro de crise da formação humana, a dimensão pedagógica de Auschwitz advém da compreensão de que tanto o projeto educacional de emancipação concebido a partir do esclarecimento, quanto o sofrimento do povo judeu na Segunda Guerra Mundial são produtos da mesma racionalidade e somente foram possíveis por sua causa. Ambos são movimentos de reprodução da mesma lógica do projeto da modernidade e, nessa medida, convocam a buscar identificar quais são os elementos sociais de obliteração da verdadeira emancipação racional e a procurar compreender a pressão que o todo social é capaz de exercer sobre o sujeito, impedindo a sua saída do estado de menoridade e provocando a manutenção da sociedade na barbárie:

A barbárie não é a filha bastarda do capitalismo burguês e sim geração permanente das entranhas de seu desenvolvimento. Na conferência 
radiofônica de abril de 1965, 'Educação após Auschwitz', [Adorno] chama por Freud para expressar esse princípio norteador: a civilização produz a anticivilização e a reforça progressivamente. As condições objetivas que produziram a recaída na barbárie de Auschwitz, de Nagasaki, substancialmente permaneceram, sua maldição não foi ainda exorcizada. A dizimação, pela guerra e pela fome, de nações africanas, as mutilações/mortes cotidianas de pessoas inocentes no Rio e em São Paulo, vítimas das gangues das drogas e da violência urbana generalizada, são apenas alguns exemplos da trágica atualidade das análises adornianas sobre a permanência das condições objetivas que geram a barbárie. (PUCCI, 1997, p. 14).

Com isso, compreende-se a atualidade e a pertinência de continuar pensando sobre e resistindo contra as causas que determinam a manutenção do ser humano em um estado de racionalidade estéril e da importância (e possibilidades) da educação nesse processo. Ainda que pareça óbvio que o evitamento da barbárie é uma preocupação imperativa, existe ofuscamento acerca do tratamento adequado do potencial pedagógico da memória. Confunde-se (propositalmente) o dever de memória, por exemplo, com a simples mudança no nome de ruas, logradouros, praças etc. 0 dever de memória não se trata de "[...] apelo a comemorações solenes; é, muito mais, uma exigência de análise esclarecedora que deveria permitir - e isso é decisivo - fornecer instrumentos de análise para melhor esclarecer o presente" (GAGNEBIN, 2003, p. 41).

O ofuscamento deliberado da importância do conceito de dever de memória pode ser compreendido a partir de, ao menos, duas ordens de resistência à sua consideração como fundamento político-educacional: existem aqueles que são sabedores do que significa contar a história e encarar a realidade a partir dessa perspectiva e temem as consequências emancipatórias do dever de memória; e, outros, que se declaram preocupados com um suposto processo de vingança ou revanchismo que decorreria desse movimento de justiça histórica.
Com relação aos primeiros, não se trata de uma questão argumentativa ou de convencimento, trata-se de uma posição política consciente com o objetivo de manutenção do status quo. É o caso da posição dos países europeus com relação à exigência de visto para os moradores de suas colônias do passado. Reyes Mate ilustra essa afirmação mediante a análise da carta escrita por um grupo de intelectuais colombianos, encabeçados por García Márquez, em 2000, dirigida aos espanhóis com relação à exigência de visto para os sul-americanos ingressarem na Europa:

Somos filhos, ou se não filhos, netos ou bisnetos da Espanha. E quando não nos une um nexo de sangue, nos une uma dívida de serviço; somos os filhos ou os netos dos escravos e os servos injustamente submetidos pela Espanha. Não nos poderemos somar em um instante para ressaltar a importância de nossa língua e de nossa cultura, e logo depois sobrarmos quando for conveniente para a Europa. Explicai aos vossos sócios europeus que todos vós tendes conosco uma obrigação e um compromisso históricos aos quais não podem dar as costas. (MÁRQUEZ, 1967 apud MATE, 2005, p. 8).

Com relação aos que temem um processo de vingança ou revanchismo que surgiria do reposicionamento da memória do sofrimento como fundamento ético para se (re)pensar a história, há uma expressiva quantidade de produção científica, em diversas das ciências sociais e nas artes (literatura, cinema, fotografia etc.), que desautoriza essa maneira de pensar. 0 dever de memória não visa a vingança, mas, sim, a justiça necessária: a) para prestar algum significado ao sofrimento das vítimas da história; e b) para possibilitar às gerações presente e futura o aprendizado necessário para que o sofrimento (fruto da injustiça) não se repita. A produção intelectual sobre a questão pode ser entendida a partir da expressiva quantidade de eventos de barbárie ocorridos no século passado, que forçaram o ser humano a se questionar sobre a necessidade do estabelecimento de uma memória coletiva com força imperativa para 
invadir e cobrar do presente a responsabilidade histórica.

Desde iniciativas individuais, da sociedade civil, até políticas institucionalizadas têm-se mobilizado em torno da necessidade do estabelecimento de uma memória histórica como processo de justiça. ${ }^{13}$ Em nível estatal, muitas decisões judiciais (e condenações) foram proferidas em processos que, pela regra ordinária dos procedimentos jurisdicionais, seriam considerados prescritos: legislações, ${ }^{14}$ instauração de comissões, ${ }^{15}$ órgãos estatais preocupados

13 Possivelmente por ter sofrido com uma das ditaduras mais violentas e cruéis da América do Sul, a Argentina se destaca como o país que conta com um maior número de iniciativas comprometidas com a justiça histórica: “Con la transición a la democracia se liberó en la Argentina todo un conjunto de movimientos sociales y políticos (algunos ya existentes, muchos reprimidos), que pretendieron hacer justicia de los crímenes de su pasado reciente llevando a los tribunales a los responsables de la violencia originada durante el régimen anterior. Entre las asociaciones de defensa de los derechos humanos -en Argentina- destacan las Madres de Plaza de Mayo, las Abuelas de Plaza de Mayo, el Centro de Estudios Legales y Sociales (CELS), la Asamblea Permanente por los Derechos Humanos (APDH), el Movimiento Ecuménico por los Derechos Humanos (MEDH), H.I.J.O.S., etc." (MIGUEL, 2008, p. 10).

140 primeiro grande movimento jurídico no sentido de relacionar memória e aplicação da lei foi a definição do que são os crimes contra a humanidade e determinar o seu caráter imprescritível: "O art. 7o do Tribunal Penal Internacional define como Crime contra a Humanidade as seguintes condutas: a) homicídio; b) extermínio; c) escravidão; d) deportação ou transferência forçada de populações; e) encarceramento ou outra provação grave da liberdade física, em violação às normas fundamentais do direito internacional; f) tortura; g) estupro, escravidão sexual, prostituição forçada, gravidez forçada, esterilização forçada ou outros abusos sexuais de gravidade comparável; h) perseguição de um grupo ou coletividade com identidade própria, fundada em motivos políticos, raciais, nacionais, étnicos, culturais, religiosos, de gênero, como definido no parágrafo 3o, ou outros motivos universalmente reconhecidos como inaceitáveis conforme o direito internacional, em conexão com qualquer ato mencionado no presente parágrafo ou com qualquer crime da jurisdição deste Tribunal; i) desaparecimento forçado de pessoas; j) o crime de 'apartheid'; k) outro atos desumanos de caráter similar que causem intencionalmente grande sofrimento ou atentem gravemente contra a integridade física ou a saúde mental ou física, desde que praticados 'no quadro de um ataque, generalizado ou sistemático, contra qualquer população civil, havendo conhecimento desse ataque'." (TAQUARY; TAQUARY, 2014).

15 No caso da ditadura civil-militar brasileira, há a “Comissão Nacional da Verdade, instaurada pela Lei n. 12.528 em junho de 2012 com o objetivo de apurar as violações aos direitos humanos praticadas por agentes públicos, pessoas a seu serviço, com apoio ou no interesse do Estado, no com a verdade histórica etc. Ganham bastante repercussão social, também, iniciativas relativas a datas, museus, memoriais, nomes de ruas, monumentos. Iniciativas que, na maioria das vezes, causam as mais díspares manifestações tanto em nível científico quanto em termos de opinião popular. Essa disparidade decorre justamente da ausência do tratamento adequado do dever de memória na estruturação da formação humana.

Para Primo Levi (2000), a memória é um dever. É imperativo que se conte a todos os seres humanos o que alguns seres humanos foram capazes de realizar com outros; é um dever para com as vítimas que sua história seja contada e mantida viva. Para outros autores, em contrapartida, a memória coletiva, na medida em que trata de experiências traumáticas, deve ser retirada da circulação pública como forma de encerrar um ciclo de violência. Nesse sentido, há o posicionamento de David Rieff (2012, p. 13-14), manifestado em seu livro Contra la memoria,

La gente, sin duda, los estadounidenses y, supongo, los australianos de mi clase e intereses, se inclina a dedicar demasiado tiempo a lamentar la ignorancia indiferente, la actitud adoptada por defecto de tantos ciudadanos, sobre todo de los jóvenes, respecto del pasado. Deberíamos ser más prudentes con nuestros deseos. La rememoración enardeció las guerras de sucesión de Yugoslavia; sobre todo, la rememoración de la derrota serbia en Kosovo Polje en 1389. En las colinas de Bosnia aprendí a detestar, pero sobre todo a temer, la memoria histórica colectiva. $\mathrm{Al}$ apropiarse de la historia, mi pasión perdurable y mi refugio desde la infancia, la memoria colectiva lograba que la propia historia no pareciera sino un arsenal de armas necesarias

período compreendido entre 18 de setembro de 1946 até 05 de outubro de 1988. [...] As Comissões da Verdade são mecanismos de apuração de abusos e violações de Direitos Humanos, sendo utilizadas como uma forma de esclarecer um passado arbitrário (normalmente aplicadas em países emergentes de períodos de exceção ou de guerras civis). Seu funcionamento se dá com um registro apurado do passado por meio da oitiva de vítimas e familiares de vítimas de arbitrariedades cometidas, assim como dos perpetradores dessas violências; ainda, pela análise de documentos oficiais e de arquivos ainda não conhecidos." (OLIVEIRA, 2012). 
para continuar las guerras o para mantener una paz endeble y fría. Lo que presencié en Bosnia, en Ruanda, en Kosovo, en Israel-Palestina y en Irak no me ha dado razón alguna para cambiar de parecer.

De tudo isso, o posicionamento da memória do sofrimento acumulado na história como fundamento educacional deve servir como uma oportunidade para a sociedade reconhecer os seus erros, suas barbáries, e promover a única justiça verdadeiramente possível depois do cometimento da injustiça que é a justiça histórica (a justiça na história). Essa é a tese central de Reyes Mate (2011, p. 291-292, grifo do autor), especialmente desenvolvida em seu Tratado de la Injusticia:

Sin memoria no hay injusticia. Esto lo entendió bien Horkheimer cuando decía que el crimen es evidente a quien lo comete y a quien lo sufre, pero, si éstos desaparecen, sólo será accesible a las generaciones siguientes si hay alguien que los recuerda. Sin esa memoria es como si la injusticia no hubiera ocurrido nunca y el mundo pudiera organizarse como si la barbarie no hubiera tenido lugar. Si el proyecto nazi sobre los judíos hubiera triunfado, hoy los jóvenes de Oswiecim jugarían tan felices a fútbol sobre los campos de Auschwitz, como si nada hubiera ocurrido. Se entenderá por qué el vencedor, es decir, el que comete la injusticia, no da por terminada la faena con la perpetración del acto. Sabe que tiene que afanarse también en que los demás olviden. Y es que en el mismo crimen no con un burdo negacionista, sino privando de significado al crimen. La cultura occidental ha sido maestra en la invibilización del crimen. [...] Sin memoria, tampouco hay justicia. Sin memoria no hay, pues, injusticia, pero tampouco justicia. Eso plantea un colosal problema porque lo que se está queriendo decir es que sin memoria de todas las injusticias no hay teoría posible de la justicia ya que la idea de teoría conlleva la de universalidad. [...] Reconocer la deuda con el pasado y hacer duelo por los sufrimientos sobre los que está construido nuetro bienestar. Es desde luego una forma muy modesta de justicia pero es fundamental. Si renunciáramos a ella, estaríamos diciendo que la justicia si mide por el verdugo, por su capacidad de reparación o por el castigo que se le puede infligir, y no por los daños causados a las víctimas. Por eso es importante la memoria de la injusticia, porque aunque no conlleve reparación material del daño, reconoce la vigencia del derecho de las víctimas a pedir justicia.

Nesse sentido, por óbvio, mas ainda assim importante registrar, o NIC não é uma tentativa de defender o povo judeu da repetição de uma nova chacina; trata-se de um chamado à reflexão sobre a capacidade da civilização de produzir barbárie. Por conta disso, Adorno (1995) afirma, em diversas passagens da obra Educação e Emancipação, que a desbarbarização é um dos mais importantes objetivos da educação, e a escola é uma instituição fundamental nessa tarefa. A desbarbarização é fundamental, inclusive, como forma de garantir a sobrevivência da humanidade. Em razão disso, o dever de memória é apontado como o caminho para colocar em contato as novas gerações com a barbárie produzida; mais do que simplesmente contar a história, formar a responsabilidade para com a história, especialmente para com o sofrimento das vítimas do movimento de progresso. Contudo, para atingir esse objetivo central para a sobrevivência da humanidade é imperioso que a sociedade esteja formada e comprometida com a criação e a manutenção das condições favoráveis ao evitamento da barbárie. Preocupação que não se verifica na lógica de lucro a qualquer custo do capitalismo tardio.

\section{Considerações finais}

De todo o exposto, o interesse na vinculação entre dever de memória e emancipação, proposta no presente artigo, tem como fundamento a compreensão adequada do dever de memória a partir da elaboração do passado decorrente do NIC no projeto de desbarbarização da educação e da sociedade, pois, conforme afirma Reyes Mate (2005, p. 138): "Se a barbárie voltou a ocupar lugar, pode ser devido, segundo a tese de Adorno, porque não soubemos recordar." Nesse sentido, a relação entre dever de memória e emancipação é para 
o evitamento da permanência da barbárie na sociedade esclarecida.

Para tanto é necessário identificar e compreender quais as formas pelas quais a sociedade burguesa se apropria e reforça a lógica de esquecimento daquilo que não se enquadra dentre as prioridades do mercado e administra a sociedade a partir de interesses econômicos, impondo obstáculos às possibilidades do "saber recordar" necessário à emancipação. A partir disso, a memória do sofrimento surge como comprometimento político necessário para pensar-se em justiça: "sin memoria no hay justicia” (MATE, 2013, p. 150). A humanização do humano, entendida como objetivo principal do processo educacional, somente se dá - entenda-se como comprometida com a justiça - quando a memória do sofrimento está na base de sua estruturação.

\section{REFERÊNCIAS}

ADORNO, Theodor W. Dialética negativa. Rio de Janeiro: Zahar, 2009.

Educação e emancipação. Rio de Janeiro: Paz e Terra, 1995.

. Minima moralia. São Paulo: Ática, 1993.

ADORNO, Theodor W.; HORKHEIMER, Max. Dialética do Esclarecimento. Rio de Janeiro: Zahar, 1985.

ARENDT, Hannah. Entre o passado e o futuro. São Paulo: Perspectiva, 2007.

BUCK-MORSS, Susan. Origen de la dialéctica negativa. Theodor W. Adorno, Walter Benjamin, y el Instituto de Frankfurt. México: Siglo Veintiuno, 1981.

CROCHÍK, José Leon. T. W. Adorno e a psicologia social. Psicologia \& Sociedade, v. 20, n. 2, p. 297 305, 2008.

CUNHA, Renata Cristina da. Adorno, Theodor W. Educaçao e emancipação. Linguagens, Educação e Sociedade, Teresina, ano 12, n. 17, p. 95-99, jul./ dez. 2007.

DUTRA, Claudia; MORENO, Camila. Escola Sem Partido: estratégia golpista para calar a educação. Carta Capital, São Paulo, 08 ago. 2016. Disponível em: <http://www.cartacapital.com.br/educacao/ escola-sem-partido-estrategia-golpista-para-calar -a-educacao>. Acesso em: 28 dez. 2016.

FOUCAULT, Michel. A ordem do discurso. 2. ed. São Paulo: Loyola, 1996.

GAGNEBIN, Jeanne-Marie. 0 que significa elaborar o passado? In: PUCCI, Bruno; LASTÓRIA, Luiz Antônio; COSTA, Belarmino (Org.). Tecnologia, cultura e formação... ainda Auschwitz. São Paulo: Cortez, 2003. p. 35-44.

GOERGEN, Pedro. Educação e valores no mundo contemporâneo. Educação e Sociedade, Campinas, SP, v. 26, n. 92, p. 983-1011, out. 2005.

Formação ontem e hoje. In: CENCI, Angelo Vitório; DALBOSCO, Cláudio Almir, MÜHL, Eldon Henrique (Org.). Sobre filosofia e educação: racionalidade, diversidade e formação pedagógica. Passo Fundo, RS: Editora da Universidade de Passo Fundo, 2009. p. 25-63.

GOMES, Luiz Roberto. Teoria crítica da educação: experiências atuais de pesquisa no Brasil e na Alemanha. Comunicações, Piracicaba, SP, ano 22, n. 3, p. 145-154, 2015.

HOKHEIMER, M. Teoria Tradicional e Teoria Crítica. São Paulo: Abril Cultural, 1980. (Coleção Os Pensadores).

KANT, Immanuel. Fundamentação da metafísica dos costumes. Tradução Paulo Quintela. Lisboa: Edições 70, 2004.

Resposta à pergunta: que é esclarecimento (Aufklärung)? In: RJ: Vozes, 2005. p. 63-71. Textos seletos. Petrópolis,

LEVI, Primo. É isto um homem? Trad. Luigi del Rey. 3. ed. Rio de Janeiro: Rocco, 2000.

MAAR, Wolfgang Leo. À guisa de introdução: Adorno e a experiência formativa. In: ADORNO, Theodor. Educação e emancipação. São Paulo: Paz e Terra, 1995. p. 11-28.

MATE, Reyes. La piedra desechada. Madrid: Trotta, 2013.

. Memórias de Auschwitz. São Leopoldo: Nova Harmonia, 2005.

. Tratado de la injusticia. Barcelona: Anthropos, 2011.

MIGUEL, Aitor Manuel Bolaños de. Políticas de la memoria, lucha contra la impunidad y derechos humanos en la Argentina post dictadura. Buenos Aires: UNED, 2008. Disponível em: <https://www. ucm.es/data/cont/docs/297-2013-07-29-3-08. pdf>. Acesso em: 12 jul. 2016. 
MOURA, Regina Bustamante. Violência na história. Rio de Janeiro: Mauad, 2009.

OLIVEIRA, Gabriela Goergen de. Comissão Nacional da Verdade: a busca pela concretização da justiça de transição no Brasil. 2012. 30 f. Monografia (Graduação em Direito) - Pontifícia Universidade Católica do Rio Grande do Sul (PUC-RS), Porto Alegre, 2012. Disponível em: <http://www3.pucrs.br/ pucrs/files/uni/poa/direito/graduacao/tcc/tcc2/ trabalhos2012_2/gabriela_oliveira.pdf>. Acesso em: 12 dez. 2016.

PAVIANI, Jayme. Problemas de filosofia da educação. Caxias do Sul, RS: Educs, 1983.

PUCCI, Bruno. Filosofia negativa e educação: Adorno. Filosofia, Sociedade e Educação, Marília, SP, ano 1, n. 1, p. 163-192, 1997.

Na educação escolar a frieza concretiza-se de forma especial. In: GRUSCHKA, Andreas. Frieza burguesa e educação: a frieza como mal-estar moral da cultura burguesa na educação. Campinas, SP: Autores Associados, 2014. p. XV-XXX.

RIEFF, David. Contra la memoria. Barcelona: Editorial Debate, 2012.

SAVI NETO, Pedro. Educação e memória do sofrimento em T. W. Adorno. 2017. Tese (Doutorado em Educação) - Programa de Pós-Graduação em Educação da Pontifícia Universidade Católica do Rio Grande do Sul (PUC-RS), Porto Alegre, 2017.

SOUZA, Ricardo Timm de. Totalidade \& Desagregação - sobre as fronteiras do pensamento e suas alternativas. Porto Alegre: EDIPUCRS, 1996.

TAQUARY, Eneida Orbage de Britto; TAQUARY, Catharina Orbage de Britto. Crimes contra a humanidade: o olhar da Corte Interamericana de Direitos Humanos. 2014. Disponível em: <http://www. publicadireito.com. br/artigos /?cod=84464b3e226fd6b2>. Acesso em: 12 dez. 2016.

TIEDMANN, Rolf. Sabes lo que pasará? Sobre la actualidad de la teoría de la sociedad de Adorno. In: CABOT, Mateu (Org.). El pensamiento de Th. W. Adorno. Balance y perspectivas. Palma, ES: UIB, 2007.

VILELA, Rita Amélia Teixeira. Críticas e possibilidades da educação e da escola na contemporaneidade: lições de Theodor Adorno para o currículo. Educação em Revista, Belo Horizonte, n. 45, p. 223-248, jun. 2007.

WIGGERSHAUS, Rolf. A Escola de Frankfurt: história, desenvolvimento teórico, significação política. Rio de Janeiro: DIFEL, 2002.

ZAMORA, Jose A. Educação depois de Auschwitz. In: MOREIRA, Alberto; PUCCI, Bruno; ____. (Org.). Adorno: educação e religião. Goiânia: Editora da UCG, 2008. p. 11-27.

ZUIN, Antônio Álvaro Soares; PUCCI, Bruno; RAMOS-DE-OLIVEIRA, Newton. Adorno: o poder educativo do pensamento crítico. Petrópolis, RJ: Vozes, 2000.

Recebido em: 20/09/2017 Aprovado em: 25/01/2019 